\title{
Detection and Characterization of Rotavirus G and P Types from Children Participating in a Rotavirus Vaccine Trial in Belém, Brazil
}

\author{
JDP Mascarenhas $/{ }^{+}$, AC Linhares, YB Gabbay,JPG Leite*
}

\author{
Instituto Evandro Chagas, Fundação Nacional de Saúde, 66090-000 Belém, PA, Brasil *Departamento de Virologia, Instituto \\ Oswaldo Cruz-Fiocruz, Rio de Janeiro, RJ, Brasil
}

This study sought the characterization of rotaviruses in a trial with a tetravalent rhesus-human rotavirus vaccine in Belém, Brazil in children who received three doses of vaccine or placebo in the 1st, 3rd and 5th months of life. Rotavirus electropherotypes, subgroups, $G$ serotypes, $G,[P]$ and $[P], G$ genotypes were determined in 93.3\%, 95.9\%, $93.3 \%, 73.3 \%, 95.5 \%$ and $92.2 \%$ of isolates, respectively. Serotypes G1, G2 and G4 were detected in 58.9\%, 30\% and $4.4 \%$ of the cases, respectively. Rotavirus genotype G5 was detected for the first time in Northern region in $4.4 \%$ of the infections. Rotavirus genotypes P[8], P[4], P[6] and P[8+6] were detected in $54.5 \%, 26.7 \%, 12.2 \%$, and $2.2 \%$ of the cases, respectively. The predominant genotypes were P[8],G1 and P[4],G2 with $53 \%$ and $26.6 \%$ of the infections, respectively. Unusual strains accounted for $20.5 \%$ including $P[4], G 1, P[6], G 1, P[6], G 4, P[6], G 5, P[8], G 2, P[8], G 5$. Mixed infections involving $P[8+6], G 2$ and $P[8+6], G 1$ were also noted. The neonatal P[6] strains associated with diarrhea were detected among children aged 9-24 months. To our knowledge, this study represents the first in Brazil to analyse, on molecular basis, rotavirus genotypes from children participating in a rotavirus vaccine trial. These results are of potential importance regarding future rotavirus vaccination strategies in Brazil.

Key words: rotavirus - vaccine - genotype G - genotype P - Belém - Brazil

Rotaviruses A constitute the most important cause of severe gastroenteritis among infants and young children in developing and developed countries, accounting for about 680,000 deaths per year in developing countries (Kapikian \& Chanock 1996, Miller \& McCann 2000). Because of the high mortality-rate associated with rotavirus diarrhoea, particularly in the developing countries, the availability of an effective vaccine is a goal to be pursued.

The rotavirus belongs the Reoviridae family, genus Rotavirus. The complete viral particle is constituted by a triple-layered shell protein and the genome that consists of 11 segments of double-stranded RNA (dsRNA) each one coding a protein (Kapikian \& Chanock 1996). The proteins VP4 and VP7 induce type-specific neutralising antibodies and are involved with the immunity protection. $G$ serotype is associated with VP7 protein whereas P serotype refers to VP4 protein (Kapikian \& Chanock 1996).

Fourteen G serotypes/genotypes, of which 10 (G1-G6, G8-G10 and G12) were described infecting humans (Parashar et al. 1998), and $20 \mathrm{P}$ genotypes, as specified by the 4 th dsRNA segment; 4 of these were described infecting humans, as follows: P[4], P[6], P[8], and P[9] (Estes 1996). The serotypes G1-G4, are the most common cause of disease worldwide (Kapikian \& Chanock 1996, Gentsch et al. 1996). In developing countries other G serotypes/genotypes are important such as G5, G6, G8, G9, and G10 (Gentsch et al. 1996, Santos et al. 1998).

On the basis of the current binary proposed system for rotavirus characterization, the majority of isolates from diarrhoeic children fall into four groups: P[8],G1, P[4],G2, P[8],G3,

\footnotetext{
This work was supported by Instituto Evandro Chagas-Funasa, Instituto Oswaldo Cruz-Fiocruz, Coordenação Geral de Laboratórios-Funasa, and CNPq.

+Corresponding author. Fax: +55-91-214.2005. E-mail: joanamascarenhas@iec.pa.gov.br

Received 15 March 2001

Accepted 3 October 2001
}

and P[8],G4 (Bishop et al. 1991, Woods et al. 1992, Beards et al. 1995). Of these, $P[8], G 1$ and $P[4], G 2$ rotavirus strains are the most prevalent worldwide (Rasool et al. 1993, Das et al. 1994, Santos et al. 1994, Gentsch et al. 1996).

The present report documents the diversity of rotavirus $\mathrm{G}$ and $\mathrm{P}$ types from children participating in trial using the tetravalent rhesus-human reassortant rotavirus vaccine (RRV-TV) in Belém, Brazil.

\section{MATERIALS AND METHODS}

Patients and methods - This study was aproved by the Regional Council of Medicine of the State of Pará, the Secretary of Public Health of the State of Pará, and the Ministry of Health of Brazil, and by the Ethical Commitee of Instituto Evandro Chagas (Belém) and Ethical Review Commitee of the World Health Organization.

The study was a 2-year, prospective, double-blind, placebo-controlled, randomized trial in which infants received three doses of RRV-TV or placebo in the 1st, 3rd and 5th months of life (Linhares et al. 1996). In the present study we are considering 90 rotavirus positive cases diagnosed by enzyme immunoassay (DAKO ${ }^{\mathrm{TM}}$, Copenhagen, Denmark), involving 83 children with gastroenteritis wich received three doses of RRV-TV vaccine ( 270 children) or placebo (270 children).

$G$ serotyping and subgrouping by enzyme immunoassay - Subgrouping and G-serotyping of rotavirus-positive samples were performed essentially as described by Taniguchi et al. (1987), by using monoclonal antibodies against each of the subgroups I and II and human G1, G2, G3, and G4 serotypes, which were kindly provided by Dr Shozo Urasawa, Department of Hygiene and Epidemiology, Sapporo Medical College, Sapporo, Japan.

Polyacrylamide gel electrophoresis - The double stranded RNA was extracted from $400 \mu \mathrm{l}$ of positive suspensions follow the metodology described by Boom et al. (1990). The electrophoresis was performed using a 5\% polyacrylamide slab gels (PAGE) and the gels were then stained with silver nitrate as previously described by Pereira et al. (1983). 
Reverse transcription-polymerase chain reaction for $G$ and $P$ rotavirus genotyping - The reverse-transcription followed by polymerase chain reaction (RT-PCR) for G and $P$ rotavirus genotyping was performed in two steps, as described by Gouvea et al. $(1990,1994)$ and Gentsch et al. (1992), respectively, with modifications introduced by Leite et al. (1996). In the first amplification, a mixture of consensual primers $9 \operatorname{con} 1 / 9 \operatorname{con} 2$ or Beg/End9 (G genotype) and $4 \operatorname{con} 2 / 4 \operatorname{con} 3$ (P genotype) was used. To assess both $\mathrm{G}$ and $\mathrm{P}$ broad reactivity the mixture was cycled in a termocycler (Perkin Elmer, GeneAmp PCR System 9600), being submitted to 30 cycles of amplification. The amplicons were then eletrophoresed on $1 \%$ agarose gel in Tris-Borate-EDTA buffer (TBE) in Wide Mini-Sub Cell GT (Bio-Rad Laboratories, Hercules, CA, USA). The gel was stained with ethidium bromide $(0.5 \mu \mathrm{g} / \mathrm{ml})$ and cDNAs visualized and photographed using a system Gel Doc 1000 (Bio-Rad, Laboratories, Hercules, CA, USA).

The nested-PCR was carried out using a mixture of $G$ (G1-G5 and G9 and rotavirus animal primers Beg 9, d end 9, CRW8, end 9-6) (Gouvea et al. 1990, 1994), and P (P[4], $\mathrm{P}[6], \mathrm{P}[8]$, and $\mathrm{P}[9])$ (Gentsch et al. 1992) specific genotyping oligonucleotide primers by 30 cycles of amplification. All amplicons were subsequently subjected to electrophoresis on $1 \%$ agarose in TBE buffer containing ethidium bromide $(0.5 \mu \mathrm{g} / \mathrm{ml})$.

Southern hybridization and chemiluminescent detection - Southern hybridization with oligonucleotide probes was carried out to confirm the P (Ramachandran et al. 1996) and $G$ (Leite et al. 1996) genotype-specificities according to the method described by Ando et al. (1995), with modifications introduced by Leite et al. (1996). Dig-probes were used to discriminate between porcine G5 OSU-like strains from G5 human strains isolated from Brazilian infants, as described by Alfieri et al. (1996).

\section{RESULTS}

The PAGE showed a clear profile in $84(93.3 \%)$ out of 90 positive samples. The predominant electropherotype was long, accounting for $38(70.4 \%)$ and $24(66.7 \%)$ of tested samples in the placebo and vaccine groups (Table I).

The sub-group specificity was carried out in 70 out of $73(95.9 \%)$ positive samples, of which, sub-group II was the most prevalent, followed by sub-group I in both groups (Table I).

Serotyping was carried out on $84(93.3 \%)$ out of 90 rotavirus positive specimens. G1, G2 and G4 were detected and the most prevalent serotype was G1 in both placebo $(58.2 \%)$ and vaccine $(60 \%)$ groups (Table I). The usual correlation between subgroups and serotypes was noted in $80 \%$ of positive samples.

Nested-PCR was carried out in 90 samples to characterize the $\mathrm{G}$ rotavirus genotypes. Using $9 \operatorname{con} 1 / 9 \operatorname{con} 2$ specific primers it was possible to characterize rotavirus $\mathrm{G}$ genotype in $66(73.3 \%)$ of isolates. From 66 samples with defined G genotype, 43 (47.8\%) were genotype G1, 18 (20\%) $\mathrm{G} 2,1(1.1 \%) \mathrm{G} 4$ and $4(4.4 \%) \mathrm{G} 5$.

From the 24 remaining samples without G genotype, 19 with available specimens were tested using rotavirus animal primers Beg 9, d end 9, CRW8, end 9-6, obtained from rotavirus of animal origin, being all negatives.

From $86(95.5 \%)$ samples with defined $\mathrm{P}$ genotypes, 24 (26.7\%) were classified as genotype P[4], 11 (12.2\%) P[6], and $49(54.5 \%) \mathrm{P}[8]$. Two samples $(2.2 \%)$ showed mixed
TABLE I

Characterization of electropherotypes, subgroups, G serotypes and $P[], G$ genotypes of rotavirus A from a vaccine trial, Belém, PA, Brazil

\begin{tabular}{lllll}
\hline & \multicolumn{3}{c}{ Children group } & Total \\
\cline { 2 - 3 } & Placebo $(\%)$ & Vaccine & $(\%)$ & $(\%)$ \\
\hline Electropherotype
\end{tabular}

Electropherotype

$\begin{array}{lrrrrrr}\text { Long } & 38 & (70.4) & 24 & (66.7) & 62 & (68.9) \\ \text { Short } & 14 & (25.9) & 8 & (22.2) & 22 & (24.4) \\ \text { Not determined } & 2 & (3.7) & 4 & (11.1) & 6 & (6.7) \\ \text { Total } & 54 & & 36 & & 90 & \end{array}$

Sub-group

I

II

$\mathrm{I} / \mathrm{II}^{a}$

Not subgrouped

10

$\begin{array}{rrrrl}(21.3) & 6 & (23.1) & 16 & (22) \\ (70.3) & 16 & (61.5) & 49 & (67.1) \\ (4.2) & 3 & (11.5) & 5 & (6.8) \\ (4.2) & 1 & (3.9) & 3 & (4.1) \\ & 26 & & 73^{b} & \end{array}$

Total

G Serotype

G1

G2

G4

Not serotyped

$\begin{array}{llll}(58.2) & 21 & (60) & 53(58.9)\end{array}$

$\begin{array}{llll}(29.1) & 11 & (31.4) & 27 \\ (30)\end{array}$

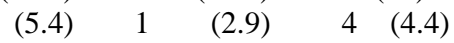

Total

$\begin{array}{lllll}(7.3) & 2 & (5.7) & 6 & (6.7)\end{array}$

G Genotype

G1

G2

4

G5

Not genotyped

55

35

90

Total

$\begin{array}{rcrcrl}26 & (47.3) & 17 & (48.6) & 43 & (47.8) \\ 11 & (20) & 7 & (20.0) & 18 & (20) \\ 1 & (1.8) & - & - & 1 & (1.1) \\ 3 & (5.4) & 1 & (2.8) & 4 & (4.4) \\ 14 & (25.4) & 10 & (28.6) & 24 & (26.7) \\ 55 & & 35 & & 90 & \end{array}$

P Genotype

$\mathrm{P}[4]$

$\mathrm{P}[6]$

$\mathrm{P}[8]$

$\mathrm{P}[8+6]$

Not genotyped

Total

$\begin{array}{rrrrr}(29.6) & 8 & (22.2) & 24 & (26.7) \\ (14.8) & 3 & (8.3) & 11 & (12.2) \\ (51.8) & 21 & (58.4) & 49 & (54.5) \\ (1.9) & 1 & (2.8) & 2 & (2.2) \\ (1.9) & 3 & (8.3) & 4 & (4.4) \\ & 36 & & 90 & \\ \end{array}$

$a$ : reactivity with both subgroups (I and II); $b$ : for sub-group were tested only 73 samples.

infections $\mathrm{P}[8+6]$ (Table I). The P[6] genotype was observed in both placebo and vaccine groups involving diarrhoeic children with ages between 9 and 24 months (data not shown).

The binary characterization [P],G was possible in 83 $(92.2 \%)$ out of 90 positive samples. The predominant combination was the usual genotypes: P[8],G1 (53\%) and $\mathrm{P}[4], \mathrm{G} 2$ (26.6\%). Unusual genotypes or mixed infections were observed in $20.5 \%$ of strains, such as: P[6],G1 (4.8\%), P[6],G4 (4.8\%), P[8],G5 (3.6\%), P[4],G1 (2.4\%), P[8],G2 (1.2\%), P[6],G5 (1.2\%), P[8+6],G1 (1.2\%) and P[8+6],G2 $(1.2 \%)$ (Table II).

Southern-hybridization using specific G1, G2, and G5 probes was carried out in 21 amplicons. Eight amplicons with expected size of genotype G1 and four with expected size of genotype G2 were confirmed as genotype G1 and G2 with the specific probes. However, only 4 out of 9 amplicons with expected size for G5 (742bp) were positive by Southern-hybridization (data not shown). Similarly, 11 samples were characterized by Southern-hybridization to 
TABLE II

$\mathrm{G}$ and $\mathrm{P}$ genotyped rotavirus strains isolated from children who received a tetravalent rhesus-human rotavirus vaccine or placebo in a clinical trial in Belém, PA, Brazil

\begin{tabular}{|c|c|c|c|c|c|c|c|}
\hline \multirow{2}{*}{ Genotype } & & \multicolumn{4}{|c|}{ Children group } & \multirow[b]{2}{*}{ Total } & \multirow[b]{2}{*}{$(\%)$} \\
\hline & & Placebo & $(\%)$ & Vaccine & $(\%)$ & & \\
\hline \multirow[t]{2}{*}{ Usual } & $\mathrm{P}[8], \mathrm{G} 1$ & 25 & (49) & 19 & $(59.5)$ & 44 & (53) \\
\hline & $\mathrm{P}[4], \mathrm{G} 2$ & 14 & (27.4) & 8 & (25) & 22 & (26.6) \\
\hline \multirow[t]{8}{*}{ Unusual } & P[6],G1 & 3 & (5.9) & 1 & (3.1) & 4 & $(4.8)$ \\
\hline & $\mathrm{P}[6], \mathrm{G} 4$ & 3 & (5.9) & 1 & (3.1) & 4 & (4.8) \\
\hline & P[8],G5 & 2 & (3.9) & 1 & (3.1) & 3 & (3.6) \\
\hline & P[4],G1 & 2 & (3.9) & - & - & 2 & (2.4) \\
\hline & $\mathrm{P}[8], \mathrm{G} 2$ & - & - & 1 & (3.1) & 1 & (1.2) \\
\hline & P[6],G5 & 1 & (2) & - & - & 1 & $(1.2)$ \\
\hline & $\mathrm{P}[8+6], \mathrm{G} 1^{a}$ & 1 & (2) & - & - & 1 & (1.2) \\
\hline & $\mathrm{P}[8+6], \mathrm{G} 2$ & - & - & 1 & (3.1) & 1 & $(1.2)$ \\
\hline \multicolumn{2}{|l|}{ Total } & 51 & & 32 & & 83 & \\
\hline
\end{tabular}

a: $\mathrm{P}[8+6]$ : P mixed genotypes

$P$ genotypes and, four reacted specifically with the probe $\mathrm{P}[6]$, three with probe $\mathrm{P}[8]$, two with probe $\mathrm{P}[4]$ and two with both probes $\mathrm{P}[8]$ and [6] (data not shown).

\section{DISCUSSION}

This is the first study in Brazil to determine the $\mathrm{G}$ and $\mathrm{P}$ rotavirus genotypes circulating among children participating in a vaccine trial carried out in Belém. To our knowledge, characterization of $\mathrm{P}$ genotypes has not been performed in previous vaccine trials worldwide (Clark et al. 1995, Lanata et al. 1996, Linhares et al. 1999).

In the present investigation it was observed an usual correlation of subgroup/serotype in $80 \%$ of positive cases. Similar rates were reported by Mohamed et al. (1994) in a study involving infants and young children with acute gastroenteritis in Saudi Arabia.

In this study, a high proportion (93.3\%) of samples were G-serotyped using monoclonal antibodies. This rate is higher than those observed in previous studies carried out in Belém and Goiânia, Brazil, where only $50 \%$ and $61 \%$ of samples could be serotyped (Linhares et al. 1988, Cardoso et al. 2000). It is likely that examination shortly after collection has accounted for the higher rates of G-serotyping as compared to G- genotyping. This seems to be an unusual result since almost all published studies (including those from the Brazilian groups) found that RTPCR typing greatly improves rotavirus G typing. Using primers Beg/End9 to amplify animal rotavirus strains in remaining 19 samples unsuccessfully amplified, we could postulated that those samples had mismatches in the consensual region for primer hybridization.

Among the four more epidemiologically important rotavirus $\mathrm{G}$ serotypes worldwide, three were identified in the present study: G1, G2 and G4. In addition, rotavirus genotype G5, not detected previously in the Northern Region of Brazil, occurred in $4.4 \%$ of isolates.

Santos et al. (1998), studying 49 rotavirus positive samples from diarrhoeic children from Rio de Janeiro, Brazil, found usual G1 and G3 genotypes in $27 \%$ and $12 \%$ of infection cases, followed by $61 \%$ of uncommon genotypes as G5 (25\%), G10 (16\%), G8 (5\%), and mixed G types (16\%). In the present investigation, the serotype G1 was detected in $58.9 \%$ of tested strains, whereas no G3 was recorded. In contrast, rotavirus serotypes $\mathrm{G} 2$ and $\mathrm{G} 4$ accounted for $30 \%$ and $4.4 \%$ of isolates, respectively. The results obtained in the present study were similarly to those obtained in the United Kingdon by Beards and Graham (1995), who identified $\mathrm{G} 1, \mathrm{G} 2, \mathrm{G} 3$, and $\mathrm{G} 4$ in $93 \%$ of isolates.

Linhares et al. (1988), in a study carried out in Belém from December 1982 to March 1986, showed that serotype G1 was the most prevalent (50\%), followed by G2 (30\%), G4 (17\%) and G3 (3\%). In addition, Cardoso et al. (2000), during study conducted in Goiânia, from 1987 to 1994 recorded the following rotavirus serotypes: G1 (32\%), G2 (46\%), G3 (16\%), G4 (2\%), and G5 (4\%).

This investigation showed relative frequencies of genotypes which differ from those found in another study carried out in Belém, from November 1992 to November 1994, when rotavirus serotype G2 was largely prevalent $(80 \%)$ over the other serotypes in nosocomial infections (Gusmão et al. 1995).

The rotavirus genotype G5 was identified in 1991 (two isolates) and 1992 (two isolates), being detected at rates of $4.4 \%$, three in the placebo and one in the vaccine group. Three samples were characterized as genotype P[8],G5 and one as genotype P[6],G5. The five remaining samples with expected size for G5, were negative by hybridization. Probably those samples had mismatches in the consensual region at probe hybridization since no amplification could be yielded.

To date, serotype G5 has largely been detected in pigs and, at lower rates, in equines, and also in humans. Gouvea et al. (1994) detected serotype G5 in 38 faeces of the 329 samples (12\%) for Brazilian children with diarrhoea. Leite et al. (1996) recorded the genotype G5 circulating in several states of Brazil, suggesting a broad distribution of this unusual genotype in Brazil. Previous multicentric studies in Brazil have shown that rotavirus bearing P[8], G5 typespecificity may account for up to $9 \%$ of cases of acute gastroenteritis among infants and young children (Timenetsky et al. 1994, Leite et al. 1996, Cardoso et al. 2000).

Alfieri et al. (1996) by Southern-hybridization, sequencing, and RNA-RNA hybridization analysis, showed that rotavirus genotype G5 circulating in Brazil has homology with human rotavirus genotype $\mathrm{P} 8$ (Wa-like) and porcine 
rotavirus genotype G5 (OSU-like). These results suggest that these strains have naturally reassorted, involving members of both $\mathrm{P} 8(\mathrm{Wa})$ and $\mathrm{G} 5$ (OSU) rotavirus genogroups.

With regards to the characterization of $\mathrm{P}$ genotypes in the present study, $\mathrm{P}[8], \mathrm{P}[4]$ and $\mathrm{P}[6]$ accounted for $54.5 \%$, $26.7 \%$ and $12.2 \%$ of isolates, respectively. These results were similar to those observed in South Africa, where genotypes P[8], P[4] and P[6] occurred in 64\%, 22\% and $8 \%$ of cases, respectively (Mphahlele \& Steele 1995).

Working with hospitalized children in Belém, Mascarenhas et al. (1999) characterized $86 \%$ of isolates, in contrast with the present investigation when genotype $\mathrm{P}$ characterization was obtained in $95.5 \%$ of isolates.

Neonatal P[6] strains had been previously identified among asymptomatic neonates and has been regarded as avirulent (Bishop et al. 1983, Haffejee 1991). The results of the present study are, however, in contrast with those observations regarding two aspects: (i) $\mathrm{P}[6]$ was associated with diarrhoeic cases; and (ii) involved children older than 28 days.

In this study, genotypes P[8],G1 and P[4],G2 occurred in $53 \%$ and $26.6 \%$ of isolates, respectively. Leite et al. (1996), studying isolates from 9 states and the Federal District of Brazil, described the genotypes P[8],G1, P[4],G2, $\mathrm{P}[8], \mathrm{G} 3$ and $\mathrm{P}[8], \mathrm{G} 4$, in $43 \%, 12 \%, 6 \%$ and $6 \%$ of isolates, respectively. Ramachandran et al. (1998), in USA, detected $\mathrm{P}[8], \mathrm{G} 1, \mathrm{P}[4], \mathrm{G} 2$, and P[8],G3, at rates of $66.4 \%, 8.3 \%$, and $6.9 \%$ of samples, respectively.

In the present investigation it was possible to characterize $79.5 \%$ and $20.5 \%$ of the samples as usual and unusual genotypes, respectively. Leite et al. (1996), in a countrywide study in Brazil, found genotypes P[8],G5, P[6],G2, $\mathrm{P}[9], \mathrm{G} 2$ and $\mathrm{P}[9], \mathrm{G} 3$ in $12 \%$ of the situations, and mixed infections in $21 \%$ of cases. Ramachandran et al. (1998), analyzing samples in a multicenter investigation in USA identified genotypes P[6],G9, P[8],G9, P[6],G1, P[8],G2 and P[4], G1 in $9.2 \%$ of the cases. In India Ramachandran et al. (1996) observed unusual strains in $43 \%$, of tested strains with results similar to our study, if genotypes P[6],G1 and $\mathrm{P}[6], \mathrm{G} 4$ are considered.

The rotavirus genotyping in Brazil demonstrated, in general, a high rate of mixed infection and samples frequently untypeable. These results shown a complexity of serotypes/genotypes $\mathrm{G}$ in children participating in a trial with a candidate rotavirus vaccine.

The rotavirus vaccine (RRV-TV Rotashield $\AA$ ) produced by Wyeth-Ayerst Research and licensed for use in the United States, has been suspended recently, following the occurrence of intussusception among vaccinated children (CDC 1999). A newly developed candidate rotavirus vaccine, P[8],G1, of human origin, has been recently administered to children, resulting in a rate of efficacy of about $90 \%$ against rotavirus gastroenteritis (Bernstein et al. 1999). Large-scale field trials are currently under way in developing countries.

These results described above have importance regarding a future rotavirus immunization strategies in Brazil, and underscore the need for a countrywide monitoring a rotavirus G- and P-types before the introduction of a rotavirus vaccine.

\section{ACKNOWLEDGEMENTS}

To Dr Jon Gentsch and Dr Roger Glass, members of the WHO/PAHO Rotavirus Collaborating Center in the Viral Gas- troenteritis Section of the Centers for Disease Control and Prevention for providing specific primers and Drs Ronaldo Barros de Freitas, Consuelo Silva de Oliveira, Talita Furtado Monteiro for clinical support in the follow-up of children and Mr Antônio Miranda for technical support.

\section{REFERENCES}

Alfieri AA, Leite JPG, Nakagomi O, Kaga E, Woods PA, Glass RI, Gentsch JR 1996. Characterization of human rotavirus genotype P[8]G5 from Brazil by probe-hybridization and sequence. Arch Virol 141: 2353-2364.

Ando T, Monroe SS, Gentsch JR, Jin Q, Lewis DC, Glass RI 1995. Detection and differentiation of antigenically distinct small round-structured viruses (Norwalk-like viruses) by reverse transcription-PCR and Southern hybridization. J Clin Microbiol 33: 64-71.

Beards G, Graham C 1995. Temporal distribution of rotavirus G-serotypes in the West Midlands region of the United Kingdom, 1983-1994. J Diarrhoeal Dis Res 13: 235-237.

Beards GM, Desselberger U, Flewett TH 1995. Temporal and geographical distribution of human rotavirus serotypes, 1983 to 1988. J Clin Microbiol 27: 2827-2833.

Bernstein DI, Sack DA, Rothstein E, Reisinger K, Smith VE, O'Sullivan D, Spriggs DR, Ward RL 1999. Efficacy of live, attenuated, human rotavirus vaccine $89-12$ in infants: a randomised placebo-controlled trial. Lancet 354: 287-290.

Bishop RF, Barnes GL, Cipriani E, Lund JS 1983. Clinical immunity after neonatal rotavirus infection: a prospective longitudinal study in young children. N Engl J Med 309: 72-76.

Bishop RF, Unicomb LE, Barnes GL 1991. Epidemiology of rotavirus serotypes in Melbourne, Australia, from 1973 to 1989. J Clin Microbiol 29: 862-868.

Boom R, Sol CJA, Salimans MMM, Jansen CL, Wertheim-Van Dillen PME, Van Der Noordaa J 1990. Rapid and simple method for purifications of nucleic acids. J Clin Microbiol 28: 495-503.

Cardoso DD, Soares CM, Azevedo MS, Leite JP, Munford V, Racz ML 2000. Serotypes and subgroups of rotavirus isolated from children in central Brazil. J Health Popul Nutr 18: $39-43$.

CDC-Centers for Disease Control and Prevention 1999. Withdrawal of rotavirus vaccine recommendation. $M M W R 282$ : 1007.

Clark HF, White CJ, Offit PA, Stiuson D, Eiden J, Weaver S, Cho I, Shaw A, Krah D, Ellis R 1995. Preliminary evaluation of safety and efficacy of quadrivalent human-bovine reassortant rotavirus vaccine. Ped Res 37: 127A.

Das BK, Gentsch JR, Cicirello HG, Woods PA, Gupta A, Ramachandran M, Kumar R, Bhan MK, Glass RI 1994. Characterization of rotavirus strains from newborns in New Delhi, India. J Clin Microbiol 34: 1820-1822.

Estes MK 1996. Advances in molecular biology: impact on rotavirus vaccine development. J Infect Dis 174 (Suppl.): S37-S46.

Gentsch JR, Glass RI, Woods P, Gouvea V, Gorziglia M, Flores J, Das BK, Bhan MK 1992. Identification of group A rotavirus gene 4 types by polymerase chain reaction. J Clin Microbiol 30: 1365-1373.

Gentsch JR, Woods PA, Ramachandran M, Das BK, Leite JP, Alfieri A, Kumar R, Bhan MK, Glass RI 1996. Review of G and $\mathrm{P}$ typing results from a global collection of rotavirus strains: implications for vaccine development. J Infect Dis 174 (Suppl.): 30-36.

Gouvea V, De Castro L, Do Carmo Timenetsck M, Greenberg H, Santos N 1994. Rotavirus serotype G5 associated with diarrhea in Brazilian children. J Clin Microbiol 32: 1408-1409.

Gouvea V, Glass RI, Woods P, Taniguchi K, Clark FH, Forrester B, Fang ZY 1990. Polymerase chain reaction amplification and typing of rotavirus nucleic acid from stool specimens. J Clin Microbiol 28: 276-282.

Gusmão RHP, Mascarenhas JDP, Gabbay YB, Lins-Lainson Z, 
Ramos FLP, Monteiro TAF, Valente AS, Linhares AC 1995. Rotaviruses as a cause of nosocomial, infantile diarrhoea in Northern Brazil. Mem Inst Oswaldo Cruz 90: 743-749.

Haffejee I 1991. Neonatal rotavirus infections. Rev Infect Dis 13: 957-962.

Kapikian AZ, Chanock RM 1996. Rotaviruses. In BN Fields, DM Knipe, PM Howley (eds), Fields Virology, LippincottRaven, Philadelphia, p.1657-1708.

Lanata CF, Black RE, Flores J, Lazo F, Butron B, Linares A, Huapaya A, Ventura G, Gil A, Kapikian AZ 1996. Immunogenicity, safety and protective efficacy of one dose of the rhesus rotavirus vaccine and serotype 1 and 2 human-rhesus rotavirus reassortants in children from Lima, Peru. Vaccine 14: 237-243.

Leite JPG, Alfieri AA, Woods PA, Glass RI, Gentsch JR 1996. Rotavirus G and P types circulating in Brazil: characterization by RT-PCR, probe hybridization, and sequence analysis. Arch Virol 141: 2365-2374.

Linhares AC, Gabbay YB, Mascarenhas JDP, Freitas RB, Flewett TH, Beards GM 1988. Epidemiology of rotavirus subgroups and serotypes in Belém, Brazil: a three-year study. Ann Virol (Inst Pasteur) 139: 89-99.

Linhares AC, Gabbay YB, Mascarenhas JDP, De Freitas RB, Oliveira CS, Bellesi N, Monteiro TAF, Lins-Lainson Z, Ramos FLP, Valente SA 1996. Immunogenicity, safety and efficacy of rhesus-human, reassortant rotavirus vaccine in Belém, Brazil. Bull WHO 74: 491-500.

Linhares AC, Lanata, CF, Hausdorff WP, Gabbay YB, Black RE 1999. Reappraisal of the Peruvian and Brasilian lower titer tetravalent rhesus-human reassortant rotavirus vaccine efficacy trials: analysis by severity of diarrhea. Pediatr Infect Dis J 18: 1001-1006.

Mascarenhas JDP, Gusmão RHP, Barardi CRM, Paiva FL, Simões CO, Gabbay YB, Monteiro TAF, Linhares AC 1999. Characterization of rotavirus $P$ genotypes circulating among paediatric inpatients in northern Brazil. Rev Inst Med Trop São Paulo 41: 165-170.

Miller MA, McCann L 2000. Policy analysis of the use of hepatitis B, Haemophilus influenzae type B, Streptococcus pneumoniae-conjugate and rotavirus vaccines in national immunization schedules. Health Econ 9: 19-35.

Mohammed KA, El Assouli SM, Banjar ZM 1994. Human rotavirus subgroups and serotypes in children with acute gastroenteritis in Saudi Arabia from 1988 to 1992. J Med
Virol 44: 237-242.

Mphahlele MJ, Steele AD 1995. Relative frequency of human rotavirus VP4 (P) genotypes recovered over a ten-year period from South African children with diarrhoea. J Med Virol 47: $1-5$.

Parashar UD, Bresee JS, Gentsch JR, Glass RI 1998. Rotavirus. Emerg Infect Dis 4: 561-570.

Pereira HG, Azeredo RS, Leite JP, Barth OM, Sutmoller F, De Farias V, Vidal MN 1983. Comparison of polyacrylamide gel electrophoresis (PAGE), immuno-electron microscopy (IEM) and enzyme immunoassay (EIA) for the rapid diagnosis of rotavirus infection in children. Mem Inst Oswaldo Cruz 78: 483-490.

Ramachandran M, Das BK, Vij A, Kumar R, Bhambal SS, Kesari N, Rawat H, Bahl L, Thakur S, Woods PA, Glass RI, Bhan MK, Gentsch JR 1996. Unusual diversity of human rotavirus $\mathrm{G}$ and $\mathrm{P}$ genotypes in India. J Clin Microbiol 34: 436-439.

Ramachandran M, Gentsch JR, Parashar UD, Jin S, Woods PA, Holmes JL, Kirkwood CD, Bishop RF, Greenberg HB, Urasawa S, Gerna G, Coulson BS, Taniguchi K, Bresee JS, Glass RI 1998. Detection and characterization of novel rotavirus strains in the United States. J Clin Microbiol 36: 3223-3229.

Rasool NBG, Larralde G, Gorziglia MI 1993. Determination of human rotavirus VP4 using serotype-specific cDNA probes. Arch Virol 133: 275-282.

Santos N, Lima RCC, Pereira CFA, Gouvea V 1998. Detection of rotavirus types G8 and G10 among brazilian children with diarrhea. J Clin Microbiol 36: 2727-2729.

Santos N, Riepenhoff-Talty M, Clark HF, Offit P, Gouvea V 1994. VP4 genotyping of human rotavirus in the United States. J Clin Microbiol 32: 205-208.

Taniguchi K, Urasawa T, Morita Y, Greenberg HB, Urasawa S 1987. Direct serotyping of human rotavirus in stools by an enzyme-linked immunosorbent assay using serotype 1-, 2-, 3-, and 4- specific monoclonal antibodies to VP7. J Infect Dis 155: $1159-1166$.

Timenetsky MC, Santos N, Gouvea V 1994. Survey of rotavirus $\mathrm{G}$ and $\mathrm{P}$ types associated with human gastroenteritis in São Paulo, Brazil. J Clin Microbiol 32: 2622-2624.

Woods PA, Gentsch JR, Gouvea V, Mata L, Santosham M, Bai ZS, Urasawa S, Glass RI 1992. Distribution of serotypes of human rotavirus in different populations. J Clin Microbiol 30: 781-785. 
